\title{
THE
}

\section{Validation of the delinquent activities scale for incarcerated adolescents}

\author{
Racheal Reavy \\ University of Rhode Island
}

\author{
L.A.R. Stein \\ University of Rhode Island, larstein@uri.edu \\ Andrea L. Paiva \\ University of Rhode Island, apaiva@uri.edu \\ Kathryn Quina \\ University of Rhode Island, kquina@uri.edu \\ Joseph S. Rossi \\ University of Rhode Island, jsrossi@uri.edu \\ Follow this and additional works at: https://digitalcommons.uri.edu/psy_facpubs \\ This is a pre-publication author manuscript of the final, published article. \\ Creative Commons License \\ (c) (i) $\Theta \Theta$
}

This work is licensed under a Creative Commons Attribution-Noncommercial-No Derivative Works 4.0 License.

\section{Citation/Publisher Attribution}

Reavy, R., Stein, L.A.R., Paiva, A., Quina, K., \& Rossi, J. S. (2012). Validation of the delinquent activities scale for incarcerated adolescents. Addictive Behaviors, 37(7), 875-879. doi: 10.1016/

j.addbeh.2012.03.007

Available at: https://doi.org/10.1016/j.addbeh.2012.03.007

This Article is brought to you for free and open access by the Psychology at DigitalCommons@URI. It has been accepted for inclusion in Psychology Faculty Publications by an authorized administrator of DigitalCommons@URI. For more information, please contact digitalcommons-group@uri.edu. 


\title{
Validation of the delinquent activities scale for incarcerated adolescents
}

\author{
Racheal Reavya , L.A.R. Stein ${ }^{a, b, c}$, Andrea Paiva $^{c}$, Kathryn Quina $^{d}$, and Joseph S. Rossi ${ }^{a, c}$ \\ aDepartment of Psychology, University of Rhode Island, Kingston RI, USA 02881 \\ ${ }^{b}$ Rhode Island Training School, New London Ave, Cranston, RI, 02920 USA; Center for Alcohol \\ and Addiction Studies, Department of Psychiatry and Human Behavior, Brown University, RI \\ 02912 USA
}

'Cancer Prevention Research Center, University of Rhode Island, Kingston, RI 02881 USA

dUniversity of Rhode Island Feinstein Providence Campus, 80 Washington Street, Providence, RI 02903 USA

\section{Abstract}

Purpose-This study examined the validity of the Delinquent Activities Scale (DAS), based in part on the Self Reported Delinquency (SRD) scale.

Method-Participants were 190 incarcerated adolescents (85.8\% male; average age 17 years) at a juvenile correctional facility in the Northeast. While incarcerated, they were asked about substance use and delinquent activities in the 1 year prior to incarceration, as well as parental, peer, and demographic information. They were tracked at three-months post-release, given the DAS, and assessed for post-release substance use.

Results-Three factors of the DAS assess general, alcohol-involved, and marijuana-involved delinquent activities. Principal components analysis was used to develop subscales within each factor. Support was found for concurrent and predictive incremental validities of these factors and their subscales in predicting substance use, with stronger findings for the general and the alcoholinvolved factors. Subscales related to stealing showed lower validity than those related to more aggressive behaviors.

Conclusions-These analyses suggest that the factors and empirically derived subscales offer researchers and clinicians a psychometrically sound approach for the assessment of adolescent misbehaviors.

\section{() 2012 Elsevier Ltd. All rights reserved}

Correspondence concerning this article should be addressed to L.A.R. Stein, University of Rhode Island, Department of Psychology, Social Sciences Research Center, Kingston, RI 02881. Phone: (401) 874-4261; Fax: (401) 874-2830; larstein@uri.edu.

Publisher's Disclaimer: This is a PDF file of an unedited manuscript that has been accepted for publication. As a service to our customers we are providing this early version of the manuscript. The manuscript will undergo copyediting, typesetting, and review of the resulting proof before it is published in its final citable form. Please note that during the production process errors may be discovered which could affect the content, and all legal disclaimers that apply to the journal pertain.

Contributors Author A conducted literature searches and provided summaries of previous research studies.

Authors A and B contributed to the initial conception and design of analysis.

Authors $\mathrm{A}$ and $\mathrm{C}$ conducted the statistical analysis and interpretation.

Author B obtained funding for the project and data collection.

Author D provided overall supervision and area expertise.

Author E provided statistical expertise.

Author A wrote the first draft of the manuscript and all authors contributed to and have approved the final manuscript.

Conflict of Interest All authors declare they have no conflicts of interest. 


\section{Keywords}

conduct disorder; adolescents; delinquency; substance use

\section{Introduction}

Conduct Disorder (CD) is a pattern of antisocial behaviors including physical aggression, deception, and person and property crimes. Generally, incarcerated juveniles have higher rates of CD (86.2\%; Stein, 2004) than referrals in clinics (30-50\%; Kazdin, 1985). Important correlates and causative factors are noted in the literature (verbal intelligence, genetics, etc.). To evaluate the validity of the Delinquent Activities Scale (DAS), this study focuses on a subset of factors (peers, substance use) whose significance is well established.

Externalizing behavior problems are precursors to children's breaking away from their parents' sphere of influence and transitioning to deviant peer affiliations, where substance use initiation and subsequent development of CD occur (Blackson et al., 1999). Conduct problems may then occur by the attraction of aggressive children to each other (Boivin \& Vitaro, 1995).

Roughly 95\% of adolescents treated for substance use meet criteria for CD when all behaviors are considered, but only $47 \%$ meet criteria when only behaviors occurring outside of substances are considered (Brown et al., 1996). Delinquency is a predictor of adolescent substance use, both cross-sectionally and longitudinally (Stice et al., 1998).

1.3 Aims

There are several useful and valid questionnaires available to assess CD including the Child Behavior Checklist (CBCL; Achenbach, 1993) and the Diagnostic Interview Schedule for Children (DISC; Shaffer et al., 1996). Although useful, these instruments were not designed to assess specific delinquent offenses. The Self-Reported Delinquency scale (SRD; Elliott et al., 1983) is an established measure focusing on delinquent acts that often coincide with CD. It evaluates an array of delinquent acts, committed with and without the involvement of alcohol and/or marijuana. To our knowledge, previous instruments have not been validated using incremental validity, which addresses whether a measure adds to the prediction of a criterion above what can be predicted by other sources of data. Specific aims include assessing internal reliability, stability, and concurrent and predictive incremental validity.

\section{Method}

\subsection{Participants}

This study utilizes secondary data analysis; for details see Stein et al, (2011). Participants ( $N=190)$ were incarcerated adolescents. Ten participants were missing at 3-month followup. Ns will be smaller for some analyses due to some missing data. Mean age was 17.1 years $(S D=1.10), 86 \%$ were male, $32.8 \%$ White, and $77.9 \%$ had CD diagnosis.

\subsection{Procedure}

Informed written consent was obtained followed by baseline assessment during incarceration. Follow-up assessment was conducted three months after release (average time between assessments was 253 days, $\mathrm{SD}=92$ days). 


\subsection{Measures}

2.3.1 Peer influences-Adolescents were asked, "About how many of your friends use alcohol or drugs at least once per month?" and "About how many of your friends have been arrested before?"

2.3.2 Substance use-Age of first alcohol (marijuana) use was asked, with options for "have not used." At both assessments, 3-month Timeline Follow Back (TLFB) was administered assessing alcohol and marijuana use (Sobell \& Sobell, 1995). Number of heavy drinking days (NHDD) and average number of joints smoked/week (AJW) was measured.

2.3.3 Delinquent Activities Scale-With 37-items, the DAS assesses the number of times misbehaviors were committed in the year prior to incarceration (follow-up covers 3 months), the number of times alcohol and marijuana were involved in each act, and age at which the adolescent first and last committed the act. The DAS is based on the work of Dembo and colleagues (2003; 2005); Elliott et al. (1985), Huizinga (1991), Huizinga and Esbensen (1988); and the DSM-IV (APA, 1994).

\subsection{Analytic Approach}

Subscales were derived using procedures described by Redding, Maddock, and Rossi (2006). To determine the number of components to retain parallel analysis and minimum average partial correlation were used (Horn, 1965; Velicer, 1976). Internal consistencies were obtained. Stabilities were obtained (covering an 8-month period). Hierarchical regressions were conducted to determine concurrent and predictive incremental validity of subscales. Predictors were entered on step 1; step 2 DAS subscales were entered in order to determine if they added significantly to regression analyses beyond step 1 .

\section{Results}

Variables that did not meet distributional assumptions for analyses were transformed by recoding outliers as equal to one value greater than the next largest outlier.

\subsection{Creation of DAS Subscales}

Prior to scale development items were evaluated for inclusion in analyses. One item (regarding remorse for actions) was removed because it utilized a different response format. The remaining 36 items were then dichotomized into whether the behavior was exhibited (1) or not (0). Analyses were conducted separately for the general, alcohol-related, and marijuana-related items.

The DAS-General factor consisted of two subscales, "Predatory Aggression" (e.g., used a weapon) with $a=.799$, and "Stealing and Generalized Delinquency" (e.g., ran away from home overnight), $a=.685$, together accounting for $33.33 \%$ of the variance. Two subscales formed the DAS-Alcohol factor (Stealing and Impulsive Delinquency, and Predatory Aggression), with $a=.834$ and .821 , respectively, accounting for $35.62 \%$ of the variance. Two subscales formed the DAS-Marijuana factor (Stealing and Generalized Delinquency, and Drug Dealing and Aggressive Behavior), with $\alpha=.781$ and .653, respectively, accounting for $40.93 \%$ of the variance. Loadings ranged from .42 to .76 .

Internal consistencies for the factors were also calculated at follow-up. For the three aggression-related subscales, alphas were similar to those assessed at baseline: .526, .843, and .676 for General Predatory Aggression, Alcohol-Predatory Aggression, and MarijuanaDrug Dealing and Aggressive Behavior, respectively. However, alphas were lower for the three stealing and delinquency subscales: .026, .422, and .587 for General-Stealing and 
Generalized Delinquency, Alcohol-Stealing and Impulsive Delinquency, and MarijuanaStealing and Generalized Delinquency, respectively.

Stability was examined with test-retest correlations. Scores on all six subscales were significantly correlated at the two times: General Predatory Aggression $r=.348(177), p<$. 001; General-Stealing and Generalized Delinquency $r=.204(178), p=.006$; Alcohol-Stealing and Impulsive Delinquency $r=.293(178), p<.001$; Alcohol-Predatory Aggression $r=$. 377(177), $p<.001$; Marijuana-Stealing and Generalized Delinquency $r=.279(178), p<.001$; Marijuana-Drug Dealing and Aggressive Behavior $r=.237(177), p=.001$.

\subsection{Concurrent Incremental Validity (Table 1)}

Relationships between DAS General - subscales and NHDD, after controlling for demographic variables, peer influences, and age of first alcohol use, were investigated using hierarchical regression (constructs were measured at baseline). An omnibus $\mathrm{F}$ test revealed a non-significant relationship between model 1 and baseline NHDD, contributing 5.0\% of the variance, $\mathrm{F}(5,174)=1.81, p=.113$. With DAS-General subscales entered into model 2 , a significant omnibus $\mathrm{F}$ test was produced $\left(\mathrm{R}^{2}=.10, \mathrm{~F}[7,172]=2.76, p=.010\right)$. DAS-General subscales were significant predictors, holding the initial variables constant $\left(\mathrm{F}_{\text {change }}[2,172]=\right.$ 4.93, $p=.008)$. Only the General Predatory Aggression subscale was a significant predictor, $\beta=.161, t(172)=2.06, p=.041$.

Support for concurrent incremental validity of DAS-Alcohol subscales, was also found. Model 1 was again not significantly related to baseline NHDD, $\mathrm{F}(5,174)=1.81, p=.113, \mathrm{R}^{2}$ $=.05$. However, with the addition of DAS-Alcohol subscales in model $2, \mathrm{~F}(7,172)=14.06$, $p<.001$, and $\mathrm{R}^{2}$ increased to .36 , which was a significant addition holding all other variables constant: $\mathrm{F}_{\text {change }}(2,172)=42.51, p<.001$. Both alcohol-involved subscales were significant predictors: Alcohol-Stealing and Impulsive Delinquency had $\beta=.355, t(172)=$ 4.60, $p<.001$; and Alcohol-Predatory Aggression had $\beta=.299, t(172)=3.85, p<.001$.

The relationship between DAS-General subscales and baseline AJW was examined. Demographic variables, peer influences, and age of first use were significant when entered into model 1; age of first marijuana use was the only significant predictor, with a negative relationship: $\mathrm{R}^{2}=.07, \mathrm{~F}(5,174)=2.78, p=.019 ; \beta=-.26, t(174)=-3.36, p=.001$. In model 2 , entering DAS-General subscales provided a $1.4 \%$ increase in variance explained, which was not significant, $\mathrm{F}_{\text {change }}(2,172)=1.36, p=.260$.

To determine if DAS-Marijuana subscales influenced baseline AJW, another set of analyses was performed. Demographic variables, peer influences, and age of first use were again entered in the first model, with only age of first use a significant negative predictor, as indicated above. DAS-Marijuana subscales were then entered, and for model $2, \mathrm{R}^{2}=.18$, $\mathrm{F}(7,172)=5.24, p<.001$. The $10.2 \%$ increase in variance explained by DAS-Marijuana subscales was significant: $\mathrm{F}_{\text {change }}(2,172)=10.61, p<.001$. Marijuana-Involved Drug Dealing and Aggressive Behavior was the only significant subscale $(\beta=.32, t(172)=4.12, p$ $<.001)$.

\subsection{Predictive Incremental Validity (Table 2)}

Predictive incremental validity DAS-General subscales for predicting follow-up NHDD was examined using the same approach as above. All constructs were measured at baseline, except NHDD which was measured 3-months post-release. The omnibus $\mathrm{F}$ test between model 1 and follow-up NHDD was significant: $\mathrm{R}^{2}=.28, \mathrm{~F}(5,155)=11.73, p<.001$. Baseline NHDD significantly related to follow-up NHDD: $\beta=.48, t(155)=6.82, p<.001$. Model 2 was overall significantly related to follow-up NHDD $\left(\mathrm{R}^{2}=.31, \mathrm{~F}[7,153]=9.79, p\right.$ $<.001)$, with a significant $3.5 \%$ change in $\mathrm{R}^{2}\left(\mathrm{~F}_{\text {change }}[2,153]=3.85, p=.023\right)$ for DAS- 
General subscales. DAS-General Predatory Aggression was the only significant subscale ( $\beta$ $=.20, t(153)=2.76, p=.006)$.

Analyses regarding DAS-Alcohol subscales produced a significant omnibus $\mathrm{F}$ test between the initial model and follow-up NHDD: $\mathrm{R}^{2}=.28, \mathrm{~F}(5,155)=11.73, p<.001$. In model 2 , DAS-Alcohol subscales were added: $\mathrm{R}^{2}=.35, \mathrm{~F}(7,153)=11.86, p<.001 ; \mathrm{F}_{\text {change }}(2,153)=$ 9.11, $p<.001$, with DAS-Alcohol Predatory Aggression the only significant subscale $(\beta=$. $345, t(153)=3.76, p<.001)$.

The association between proposed models and follow-up AJW produced significant omnibus tests: $\mathrm{R}^{2}=.19, \mathrm{~F}(5,155)=7.33, p<.001$ and $\mathrm{R}^{2}=.23, \mathrm{~F}(7,153)=6.54, p<.001$ for models 1 and 2, respectively. All constructs were measured at baseline, except AJW, which was measured 3-months post-release. Baseline AJW contributed significantly to follow-up AJW, with $\beta=.42, t(155)=5.75, \mathrm{p}<.001$. Additionally, the inclusion of the general subscales contributed significantly over what was explained in the initial model: $\mathrm{F}_{\text {change }}(2,153)=3.87, p=.023$. The DAS-General Predatory Aggression subscale was again the only significant subscale $(\beta=.197, t(155)=2.57, p=.011)$.

Examining DAS-Marijuana subscales produced different results. There was overall significance with model 1 (see above) and model $2\left(\mathrm{R}^{2}=.21, \mathrm{~F}[7,153]=5.63, p<.001\right)$, but the $1.4 \%$ change in $\mathrm{R}^{2}$ was not significant: $\mathrm{F}_{\text {change }}(2,153)=1.30, p>.05$.

\section{Discussion}

Empirical subscales were successfully derived. Internal consistencies ranged from .653 to . 834 at baseline, but were attenuated at follow-up. This could be due to the intervening treatment adolescents had received. Stability correlations ranged from .204 to .377 ; this could be explained by the long test-retest interval ( 8 months), intervening treatment, and the fact that the subscales were developed to measure behavioral patterns at a given time, not personality traits. Of note, subscales involving aggressive behaviors seem to be somewhat more stable and have somewhat larger internal consistencies than subscales measuring stealing and delinquency. This could be because such aggressive behavior is more trait-like (see Lahey et al, 1998; Moffit et al., 1996; Loeber et al., 1998a; and Broidy et al., 2003). DAS-Alcohol subscales have good concurrent and predictive validity overall, as does the DAS-General Predatory Aggression subscale. DAS-Marijuana empirical subscales are somewhat more limited, with only the Drug Dealing and Aggressive Behavior subscale having concurrent incremental validity. Across DAS-General, Alcohol-, and Marijuanarelated subscales, those relating to stealing did not appear to have as much incremental validity as those related to more aggressive behaviors.

Future studies should seek a larger sample, with greater female representation. It would be interesting to examine use of the DAS in adult samples. Several attempts were made to enhance the credibility of self-reports in this study. Privacy was maintained at all times. Participants were aware that their responses would not result in rewards/punishments, and were aware that responses would be checked against records and biological markers. Selfreport methods using TLFB are generally reliable and valid (Dennis et al. 2004)

\section{Acknowledgments}

Role of Funding Sources Funding for this study was provided by grants from the National Institute on Drug Abuse, R01-13375 (PI, Stein) and National Institute on Drug Abuse/National Institute on Alcoholism and Alcohol Abuse, R01-18851 (PI, Stein). Neither the NIDA, nor the NIAAA, had any role in the study design, collection, analysis or interpretation of the data, writing the manuscript, or the decision to submit the paper for publication. 


\section{References}

Achenbach TM. Implications of multiaxial empirically based assessment for behavior therapy with children. Behav Ther. 1993; 24:91-116.

American Psychiatric Association. Diagnostic and statistical manual of mental disorders. 4th ed.. Author; Washington, DC: 1994.

Blackson TC, Butler T, Belsky J, Ammerman RT, Shaw DS, Tarter RE. Individual traits and family contexts predict sons' externalizing behavior and preliminary relative risk ratios for conduct disorder and substance use disorder outcomes. Drug Alcohol Depend. 1999; 56:115-131. [PubMed: 10482403]

Boivin, N.; Vitaro, F. The impact of peer relationships on aggression in childhood: Inhibition through coercion or promotion through peer support. In: McCord, J., editor. Coercion and punishment in long-term perspectives. Cambridge University Press; Cambridge: 1995. p. 183-197.

Broidy LM, Nagin DS, Tremblay RE, Bates JE, Brame B, Dodge KA, Pettit GS. Developmental trajectories of childhood disruptive behaviors and adolescent delinquency: A six-site, cross-national study. Dev Psychol. 2003; 39:222-245. [PubMed: 12661883]

Brown SA, Gleghorn A, Schuckit M, Myers MG, Mott MA. Conduct disorder among adolescent alcohol and drug abusers. J Stud Alcohol. 1996; 57:314-324. [PubMed: 8709590]

Dembo R, Schmeidler J. A classification of high-risk use. Crime Delinq. 2003; 49:201-230.

Dembo R, Walters W, Meyers K. A practice/research collaborative: An innovative approach to identifying and responding to psychosocial functioning problems and recidivism risk among juvenile arrestees. J Offender Rehabil. 2005; 41:39-66.

Dennis ML, Funk R, Godley SH, Godley MD, Waldron H. Cross-validation of the alcohol and cannabis use measures in the Global Appraisal of Individual Needs (GAIN) and Timeline Followback (TLFB; Form 90) among adolescents in substance abuse treatment. Addiction. 2004; 99(Suppl. 2):120-128. [PubMed: 15488110]

Elliott, DS.; Ageton, SS.; Huizinga, D.; Knowles, BA.; Canter, RJ. The prevalence and incidence of delinquent behavior: 1976-1980 (National Youth Survey Report No. 26). Behavioral Research Institute; Boulder, CO: 1983.

Elliott, DS.; Huizinga, D.; Ageton, S. Explaining delinquency and drug use. Sage Publications; Beverly Hills: 1985.

Horn JL. A rationale and test for the number of factors in factor analysis. Psychometrika. 1965; 30:179-185. [PubMed: 14306381]

Huizinga, D. Assessing violent behavior with self-reports. In: Milner, JS., editor. Neuropsychology of Aggression. Kluwer Academic; Boston: 1991. p. 44-76.

Huizinga, D.; Esbensen, F. Common measures of the program of research on the causes and correlates of delinquency. [Report to the Office of Juvenile Justice and Delinquency Prevention]. Huizinga; Washington DC: 1988.

Kazdin, AE. Treatment of antisocial behavior in children and adolescents. Dorsey; Homewood, IL: 1985.

Lahey BB, Loeber R, Quay HC, Applegate B, Shaffer D, Waldman I, Bird HR. Validity of DSM-IV subtypes of conduct disorder based on age of onset. J Am Acad Child Adolesc Psychiatry. 1998; 37:435-442. [PubMed: 9549965]

Loeber, R.; Keenan, K.; Russo, MF.; Green, SM.; Lahey, BB.; Thomas, C. Secondary data analyses for DSM-IV on the symptoms of Oppositional Defiant Disorder and Conduct Disorder. In: Widiger, TA., et al., editors. DSM-IV sourcebook. Vol. Volume 4. American Psychological Association; Washington, DC: 1998a. p. 465-490.

Redding C, Maddock J, Rossi J. The sequential approach to measurement of health behavior constructs: Issues in selecting and developing measures. Californian J Health Promot. 2006; 4:83101.

Shaffer D, Fisher P, Dulcan MK, Davies M. The NIMH Diagnostic Interview Schedule for Children version 2.3 (DISC-2.3): Description, acceptability, prevalence rates, and performance in the MECA study. J Am Acad Child Adolesc Psychiatry. 1996; 35:865-877. [PubMed: 8768346] 
Sobell, LC.; Sobell, MB. Addiction Research Foundation. Toronto, Canada: 1995. Alcohol timeline followback users' manual.

Stein, LAR. Preliminary findings of a randomized clinical trial in a juvenile correctional setting. Paper present at NIDA conference; Rockville, MD. 2004, December;

Stein LAR, Lebeau R, Colby SM, Barnett NP, Golembeske C, Monti PM. Motivational Interviewing for incarcerated adolescents: effects of depressive symptoms on reducing alcohol and marijuana after release. J Stud Alcohol Drugs. 2011; 72(3):497-506. [PubMed: 21513687]

Stice E, Myers MG, Brown SA. Relations of delinquency to adolescent substance use and problem use: A prospective study. Psychol Addict Behav. 1998; 12:136-146.

Velicer WF. Determining the number of components from the matrix of partial correlations.

Psychometrika. 1976; 41:321-327. 


\section{Highlights}

- A new tool for assessing adolescent misbehaviors and delinquency is validated.

- Empirically derived factors assessed general, alcohol-involved, and marijuanainvolved delinquent activities.

- Support was found for validity of these factors and their subscales in predicting substance use.

- Subscales related to stealing showed lower validity than those related to more aggressive behaviors 
N
$\frac{0}{0}$
$\frac{\pi}{-}$

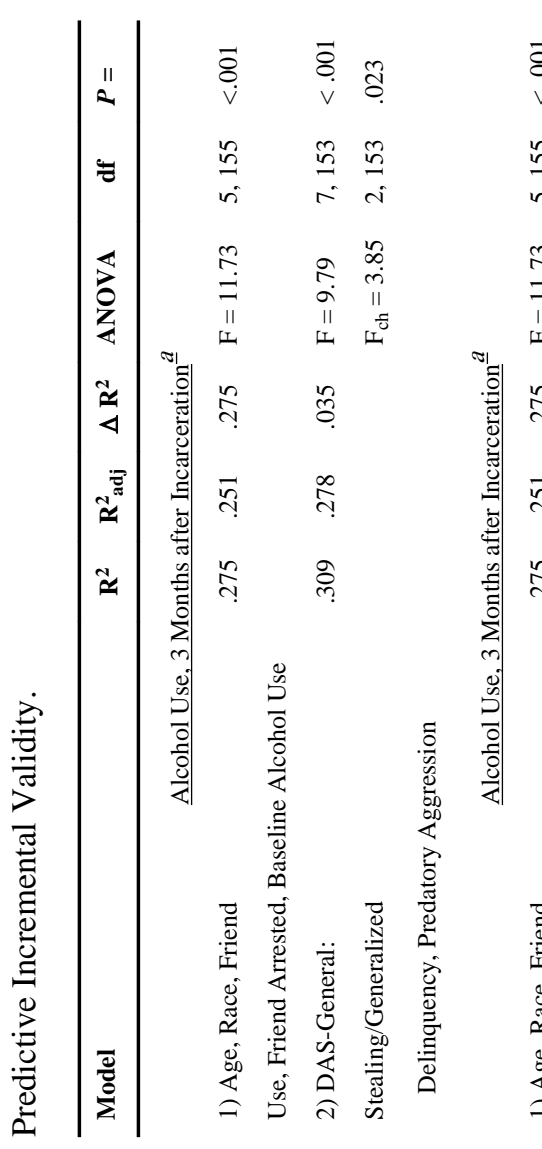

$\overrightarrow{\bar{b}} \quad \overrightarrow{\sigma_{i}} \overline{\vec{g}}$

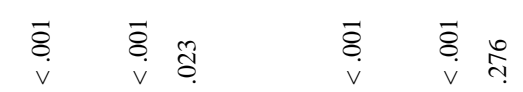

$\frac{n}{n} \quad \frac{n}{n} \frac{n}{i}$

$\frac{n}{n} \quad \frac{n}{2} \frac{n}{i} \quad \frac{n}{n} \quad \frac{n}{n} \frac{n}{i}$

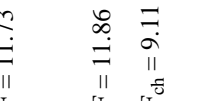

今ิ

तु तี

ते हึ่

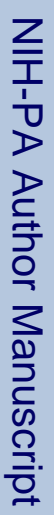

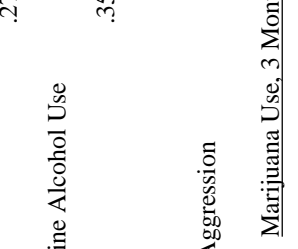

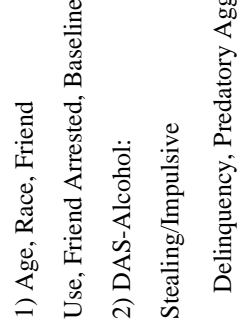

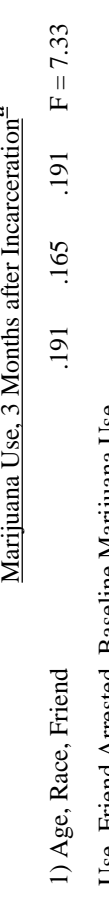

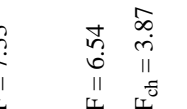

ने हे

$\ddot{2} \stackrel{\circ}{\circ}$

פ

惫

$\begin{array}{lll} & \\ & & \\ 0\end{array}$

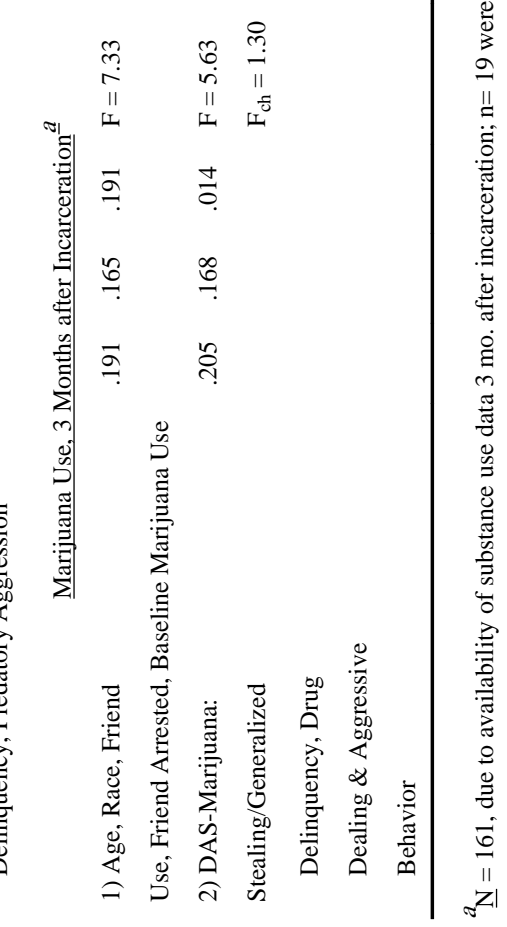

Addict Behav. Author manuscript; available in PMC 2013 July 01. 